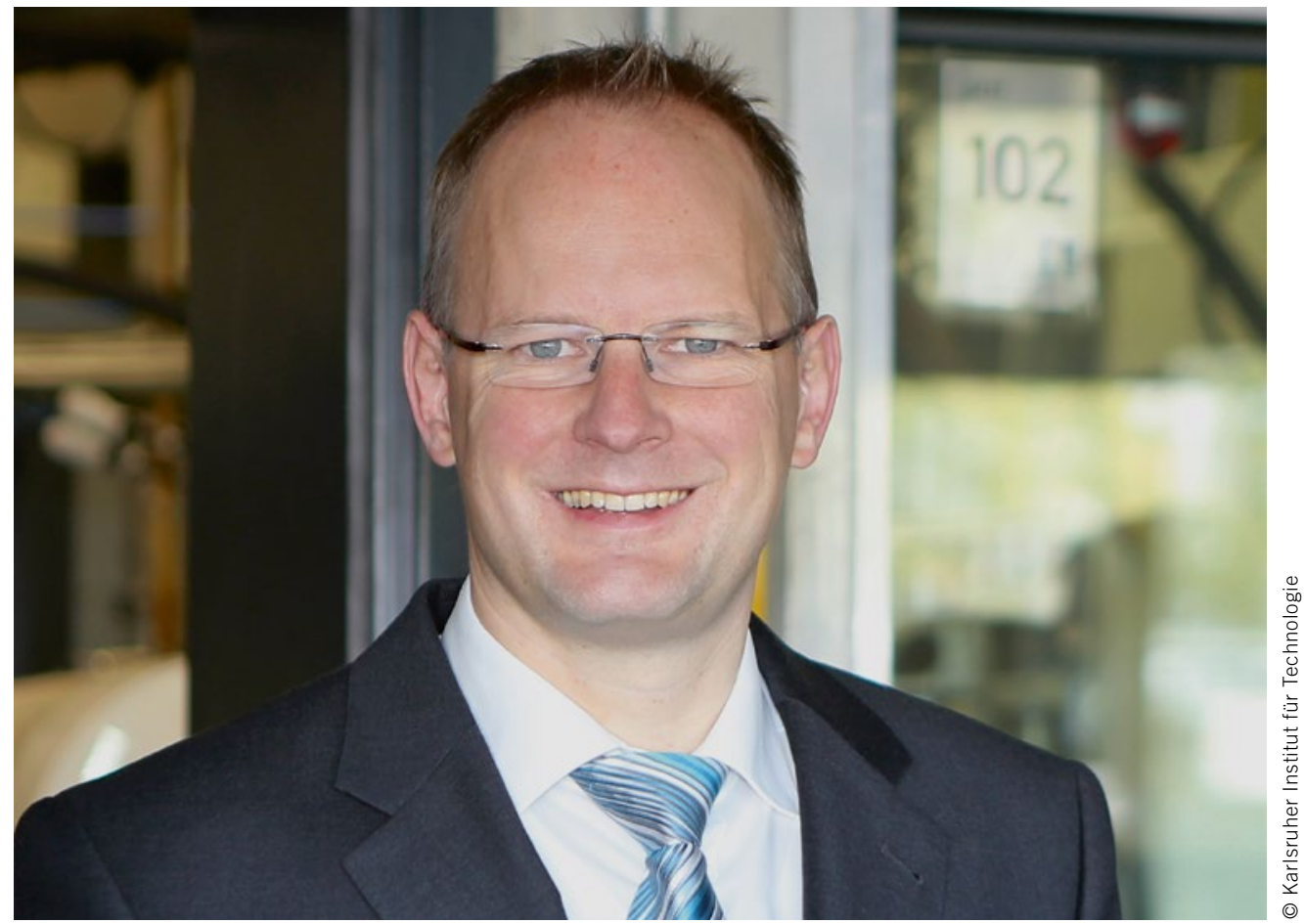

Prof. Dr. sc. techn. Thomas Koch Leiter des Instituts für Kolbenmaschinen am Karlsruher Institut für Technologie (KIT)

\title{
Paradigmenwechsel in der Automobilindustrie
}

Die Effizienzsteigerung des verbrennungsmotorischen Antriebs ist Triebfeder des Ingenieurs, seit das Automobil und der Verbrennungsmotor entwickelt werden. Die Erhöhung des Nutzwerts bei gleichzeitiger Reduktion des Energiebedarfs und der dabei emittierten Emissionen sind das Spannungsfeld, in dem eindrückliche Fortschritte mit vielen Innovationen in den vergangenen Jahren erreicht wurden. Doch während die Entwicklung in der Vergangenheit hauptsächlich die Erfüllung gesetzlicher Vorgaben mit ihren Verbrauchs- und Abgasgrenzen in engen Schranken im Fokus hatte, muss der Ingenieur von heute seine Ausrichtung deutlich verändern. Nicht mehr feste Zyklen und klar definierte Kennfeldbereiche bestimmen die Auslegung eines Verbrennungsmotors und seine Applikation im Fahrzeug. Vielmehr steht endlich die Betrachtung aller Betriebszustände mit der Einführung der gesetzlich verankerten Emissionsmessung im Realbetrieb als Aufgabe vor uns. So sehr wir messbare Größen und klare Vorgaben schätzen, müssen wir uns der mehrdimensionalen Aufgabe stellen, das Produkt in seiner Anwendung zu betrachten und unter allen sinnvollen Nutzungssituationen den Energieverbrauch und die Abgasemissionen zu optimieren. Hier kommen neue Tools sowohl beim Test des Antriebs als auch bei der Übertragung der Applikation bis hin zur Integration in die Fahrzeuge zum Einsatz.
Die breite Spreizung vom hochdynamischen Motorprüfstand bis hin zum dort komplett realisierten Antriebsstrangtest erfolgt in Kombination mit Gesamtfahrzeugsimulationen unter Berücksichtigung des Umgebungszustands. Ein kompletter Fahrzyklus wird detailliert bis in die Größenordnung einiger Mikrosekunden aufgelöst, und kritische dynamische Situationen können erkannt und bewältigt werden. Derartige Werkzeuge basieren auf dem grundlegenden Verständnis der innermotorischen Vorgänge, die in situ vermessen und in ihren Auswirkungen betrachtet werden. Dies geschieht im Einklang mit einer Weiterentwicklung der Messtechnik PEMS, die weitere Entwicklungsstufen durchlaufen wird, um noch akkuratere Messergebnisse beisteuern zu können. Auch diese Messtechnik muss abgeglichen werden mit den Messwerkzeugen der Forschung bis hin zu optischen Verfahren, die die einzelnen Spezies zeitaufgelöst detektieren. Noch immer ist die Fehlertoleranz der Messung, die sich in der Euro-6c-Gesetzgebung mit einem Sicherheitsfaktor von $50 \%$ wiederfindet, eine Herausforderung für die Entwicklung. Auf jeden Fall werden die entwickelten Motoren und Fahrzeuge weiterhin die Kunden begeistern und gleichzeitig mit ihren der Realität entsprechenden Verbräuchen und Emissionen zu einer entscheidenden Imageverbesserung des Verbrennungsmotors beitragen. 